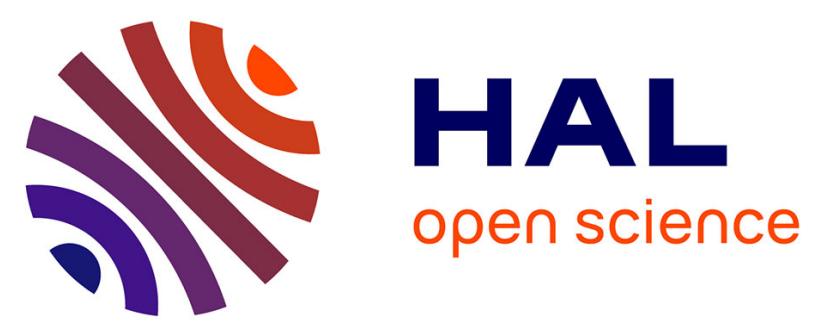

\title{
Effects of host age on susceptibility to infection and immune gene expression in honey bee queens (Apis mellifera) inoculated with Nosema ceranae
}

Veeranan Chaimanee, Panuwan Chantawannakul, Yanping Chen, Jay Evans, Jeffery Pettis

\section{To cite this version:}

Veeranan Chaimanee, Panuwan Chantawannakul, Yanping Chen, Jay Evans, Jeffery Pettis. Effects of host age on susceptibility to infection and immune gene expression in honey bee queens (Apis mellifera) inoculated with Nosema ceranae. Apidologie, 2014, 45 (4), pp.451-463. 10.1007/s13592-013-0258-x . hal-01234737

\section{HAL Id: hal-01234737 \\ https://hal.science/hal-01234737}

Submitted on 27 Nov 2015

HAL is a multi-disciplinary open access archive for the deposit and dissemination of scientific research documents, whether they are published or not. The documents may come from teaching and research institutions in France or abroad, or from public or private research centers.
L'archive ouverte pluridisciplinaire HAL, est destinée au dépôt et à la diffusion de documents scientifiques de niveau recherche, publiés ou non, émanant des établissements d'enseignement et de recherche français ou étrangers, des laboratoires publics ou privés. 


\title{
Effects of host age on susceptibility to infection and immune gene expression in honey bee queens (Apis mellifera) inoculated with Nosema ceranae
}

\author{
Veeranan Chaimanee ${ }^{1}$, Panuwan Chantawannakul ${ }^{2,3}$, Yanping $\mathrm{CHeN}^{4}$, \\ Jay D. Evans ${ }^{4}$, Jeffery S. Pettis ${ }^{4}$
}

\author{
${ }^{1}$ Section of Biotechnology, Maejo University Phrae Campus, Rong Kwang, Phrae 54140, Thailand \\ ${ }^{2}$ Bee Protection Center, Department of Biology, Faculty of Science, Chiang Mai University, Chiang Mai 50200, \\ Thailand \\ ${ }^{3}$ Materials Science Research Center, Faculty of Science, Chiang Mai University, Chiang Mai 50200, Thailand \\ ${ }^{4}$ USDA-ARS Bee Research Laboratory, Bldg. 306 BARC-E, Beltsville, MD 20705, USA
}

Received 13 February 2013 - Revised 13 August 2013 - Accepted 26 November 2013

\begin{abstract}
Nosema ceranae is a microsporidium parasite infecting honey bees worldwide. All colony members including workers, drones, and queens can become infected. In this study, we inoculated queens of age 1,6 , and 12 days post-adult emergence, with $N$. ceranae spores of different doses and allowed them to age an additional 12 days. The results indicated that younger queens were indeed more susceptible to $N$. ceranae inoculation than older queens. Moreover, this is the first report of the effects of $N$. ceranae inoculation on immune gene expression in queens of different ages. Our results demonstrated that the expression of genes related to the bee immunity apidaecin, eater, and vitellogenin in the gut and the remaining abdomen was different among queens of different ages when inoculated with $N$. ceranae. All three ages of queens inoculated by $N$. ceranae showed upregulation of apidaecin in gut tissue 6 days after inoculation, but only in queens aged 1 day post-emergence were the differences significant. However, transcript levels of eater were increased in all three ages of queens when sampled on day 12, and significant differences were obtained in queens inoculated at 6 and 12 days post-emergence. We clearly show that immune responses to $N$. ceranae changes as queen age and this knowledge may provide clues for understanding the ability of queens to resist infection by this gut parasite.
\end{abstract}

Nosema ceranae / honey bee queen / Apis mellifera / supersedure / immunity

\section{INTRODUCTION}

Two microsporidian parasites, Nosema apis and Nosema ceranae, have been reported to cause Nosema disease of honey bees. N. apis was first described in the European honey bee, Apis mellifera (Zander 1909) and N. ceranae

Corresponding author: J. Pettis, jeff.pettis@ars.usda.gov

Manuscript editor: Yves Le Conte was first known to infect the Asian cavity nesting honey bee, Apis cerana (Fries et al. 1996). However, recent studies have shown that $N$. ceranae is becoming the dominant species infecting A. mellifera worldwide and may be more virulent than $N$. apis (Fries et al. 2006; Higes et al. 2006; Chauzat et al. 2007; CoxFoster et al. 2007; Huang et al. 2007; Klee et al. 2007; Paxton et al. 2007; Chen et al. 2008; Williams et al. 2008; Chaimanee et al. 2010). Nosema infection occurs when spores are ingested through contaminated food and water 
(Webster 1993). The spores can germinate and develop in the epithelial cells of the midgut of all colony members including workers, drones, and queens. Following N. ceranae infection, the epithelial ventricular cells of infected honeybees were degenerated (Higes et al. 2007). N. ceranae has been detected not only in the midgut tissue but also other tissues including Malpighian tubules, hypopharyngeal glands, salivary glands, and fat bodies using a PCR method (Chen et al. 2009). N. ceranae can change the physiology and behavior of honey bees (Dussaubat et al. 2013; Goblirsch et al. 2013). N. ceranae infection has been reported to suppress the honey bee immune response (Antúnez et al. 2009; Chaimanee et al. 2012) and to affect hormone production by increasing ethyl oleate content (Dussaubat et al. 2010). Moreover, N. ceranae induces an energetic stress (Mayack and Naug 2009; Alaux et al. 2010; Martín-Hernández et al. 2011) and oxidative stress in honey bees (Dussaubat et al. 2012) and decreases the carbohydrate level in honeybee forager hemolymph (Mayack and Naug 2010). Similar to N. apis infection, honey bees, when infected with $N$. ceranae, have a shorter life span (Malone et al. 1995; Goblirsch et al. 2013).

Since a honey bee queen is the primary reproductive of the colony and her pheromones and presence produce cohesion between colony members, Nosema infection in queens could cause serious problems for the colony. A honey bee queen is susceptible to $N$. apis infection. In commercial queen production, a queen may become infected in the mating nuc or colony via spore ingestion from infected attendants bees in shipment or upon placement in a new colony. Nosema-infected queens have smaller ovaries when compared to the non-infected queens (Farrar 1947). Eggs of infected queens show decreased hatching rates and queens are often rapidly superseded once they become infected (Farrar 1947). Similarly, N. ceranae can be transmitted horizontally from infected worker bees to queens and can affect the epithelial ventricular cells of queens (Higes et al. 2009). Low levels of $N$. ceranae were detected in tissues of the head, thorax, abdomen, and ovaries from naturally infected queens (Traver and Fell 2012). Recently, Alaux et al. (2011) explored the effects of $N$. ceranae on honey bee queen physiology. Their results demonstrated that $N$. ceranae infection affected the physiological functions and modified pheromone production of queens. This may explain the rapid replacement of infected queens.

In this study, to demonstrate the susceptibility of queens to $N$. ceranae infection, we determined the rate of $N$. ceranae infection in queens of different ages (queens aged for 1, 6 and 12 days post-adult emergence). We hypothesized that younger queens would be more susceptible to $N$. ceranae infection than older queens. The 12-day period was selected as it corresponds with the time that queens often spend in small nucleus colonies for mating before being shipped to the beekeeper. If queens are more susceptible during this initial period of adult life then infection-mitigation measures could improve queen health and queen longevity in colonies. Moreover, even though there are some published studies about the effects of $N$. ceranae on immune response of honey bees, little is known about molecular defense mechanisms of honey bee queens to defend themselves from pathogen infections. Hence, the immune responses of honey bee queens to $N$. ceranae infection were also investigated.

\section{MATERIALS AND METHODS}

\subsection{Honey bee queens}

The experiments were conducted in August 2010 in Beltsville, MD. Queen cells containing queens of mixed A. mellifera mellifera/A. mellifera ligustica stock were obtained from a single queen breeder in Georgia, USA. Queen cells were placed individually in new wooden Benton cages and held at $34 \pm 2{ }^{\circ} \mathrm{C}$. The queens emerged within $12 \mathrm{~h}$ and were held in individual new cages containing three newly emerged worker bees from a colony with no detectable Nosema. Queens aged 1, 6, and 12 days post-adult 
emergence were used in this study. Upon emergence, ten queens were randomly sampled and checked for the presence of microsporidian spores using light microscopy and diagnostic PCR amplification (Chen et al. 2008).

\subsection{Inoculum preparation}

On each day of inoculation, $N$. ceranae spores were isolated from a colony infected with $N$. ceranae obtained from an apiary at the Bee Research Laboratory, USDA-ARS in Maryland, USA. The midguts were removed and crushed in $1 \mathrm{ml}$ of distilled water and $N$. ceranae was confirmed using PCR amplification following methods described by Chen et al. (2008). Additionally, the numbers of spores were estimated by counting spores with light microscopy after the method of Cantwell (1970). The inoculum was freshly prepared in various concentrations by mixing with $50 \%$ sucrose solution to obtain a final concentration of $10^{3}, 10^{4}, 10^{5}$, and $10^{6}$ spores/ $\mathrm{ml}$ and maintained at room temperature until used for inoculation on that day.

\section{3. $N$. ceranae inoculation experiment}

Queens of three ages: 1, 6, and 12 days post-adult emergence, were used in this study. Each age group of queens ( $n=150$ total) were held individually in new standard wooden queen cages with three newly emerged uninfected attendants. The top of each cage had a single hole that allowed for a $0.5-\mathrm{ml}$ tube containing sucrose solution $(500 \mu \mathrm{l})$ to serve as a food source. For each age group, 30 queens were fed with $50 \%$ sucrose solution containing $10^{3}, 10^{4}, 10^{5}$, and $10^{6}$ spores $/ \mathrm{ml}$ of $N$. ceranae for the first 2 days and the control group was fed with only $50 \%(w / v)$ of sucrose solution. After exposure to $N$. ceranae, queens were fed ad libitum with a clean $50 \%(w / v)$ of sucrose solution throughout the remainder of the experiment. Six queens in each group were collected at day 6 and 12 post-inoculation to be examined for $N$. ceranae infection. The individual queen guts were homogenized in $1 \mathrm{ml}$ of distilled water and $N$. ceranae spores were estimated using a hemocytometer (Cantwell 1970).

\subsection{Effects of $N$. ceranae inoculation on expression of genes related to the bee immunity}

\subsubsection{RNA isolation and cDNA synthesis}

Total RNA was isolated from the rest of gut and remaining abdomen tissues of the individual queens (control queens and queens when the cage in which the queen was received a spore suspension with $10^{5}$ and $10^{6}$ spores/ml of $N$. ceranae) using TRIzol reagent (Invitrogen, Carlsbad, CA) according to the manufacturer's protocol. DNA was removed using DNAse I incubation at $37^{\circ} \mathrm{C}$ for $1 \mathrm{~h}$ followed by $10 \mathrm{~min}$ at $75^{\circ} \mathrm{C}$. First-strand cDNA was generated from approximately $2 \mu \mathrm{g}$ total RNA using a master mix containing $50 \mathrm{U}$ Superscript II (Invitrogen, Carlsbad, CA), 2 nmol dNTP mix, $2 \mathrm{nmol}$ poly $(\mathrm{dT})_{18}$, and $0.1 \mathrm{nmol}$ poly $(\mathrm{dT})_{(12-18)}$. Synthesis was carried out at $42{ }^{\circ} \mathrm{C}$ for 50 min followed by $15 \mathrm{~min}$ at $70^{\circ} \mathrm{C}$ as described in Evans (2006).

\subsubsection{Quantitative PCR amplification}

Real-time quantitative PCR amplification was performed in a $20-\mu 1$ reaction mixture using the EXPRESS SYBR $^{\circledR}$ GreenER ${ }^{\mathrm{TM}}$ qPCR SuperMix Universal (Invitrogen) and $0.2 \mu \mathrm{M}$ of each specific primer. The oligonucleotide amplification primers are shown in Table I. The PCR reactions were carried out in 96-well microtiter plates using Bio-Rad Icycler (Bio-Rad Crop., Hercules, CA). The amplification was programmed as follows: $95^{\circ} \mathrm{C}$ for $2 \mathrm{~min}$ followed by 40 cycles of $95^{\circ} \mathrm{C}$

Table I. Oligonucleotide primers used in this study for real-time quantitative PCR (Simone et al. 2009).

\begin{tabular}{ll}
\hline Primer name & Sequence $5^{\prime}$ to $3^{\prime}$ \\
\hline Actin-F & TTGTATGCCAACACTGTCCTTT \\
Actin-R & TGGCGCGATGATCTTAATTT \\
AmEater-F & CATTTGCCAACCTGTTTGT \\
AmEater-R & ATCCATTGGTGCAATTTGG \\
ApidNT-F & TTTTGCCTTAGCAATTCTTGTTG \\
ApidNT-R & GTAGGTCGAGTAGGCGGATCT \\
VgMC-F & AGTTCCGACCGACGACGA \\
VgMC-R & TTCCCTCCCACGGAGTCC \\
\hline
\end{tabular}


for $20 \mathrm{~s}, 60^{\circ} \mathrm{C}$ for $30 \mathrm{~s}$ and $72{ }^{\circ} \mathrm{C}$ for $80 \mathrm{~s}$. Fluorescence was measured repeatedly each cycle during the annealing step. This procedure was followed by a melt-curve dissociation analysis to confirm product size.

The amplification results were expressed as the threshold cycle $\left(C_{\mathrm{t}}\right)$ value, which represented the number of cycles needed to generate a fluorescent signal greater than a predefined threshold. Threshold cycle numbers for the target gene were subtracted from the reference gene ( $\beta$-actin) for each sample. The amplification efficiency for target and control products was established via serial dilutions of known templates (e.g., Chen et al. 2008; Simone et al. 2009; Cornman et al. 2012).

\subsection{Expression levels of genes related to the bee immunity in gut and remaining abdomen of queens at different ages}

Control queens from ages $6(n=6), 12(n=12), 18$ $(n=12)$, and $24(n=6)$ days following adult emergence were analyzed. Total RNA was isolated from gut and remaining abdomen tissues of the individual queens using TRIzol reagent (Invitrogen, Carlsbad, CA) according to the manufacturer's protocol. cDNA synthesis and quantitative PCR amplification were described above (Sections 2.4.1 and 2.4.2).

\subsection{Statistical analysis}

Normality of data was checked using SPSS version 17.0 for Windows (SPSS, Inc.). Statistical significance was analyzed using ANOVA if they fitted a normal distribution. However, where the data were not normally distributed, the nonparametric Kruskal-Wallis $H$ and Mann-Whitney $U$ test were applied.

\section{RESULTS}

\subsection{N. ceranae infection of queens aged 1 , 6, and 12 days after emergence}

When fed with $N$. ceranae spores at different doses, $N$. ceranae spores were quantified 6 and 12 days post-inoculation. No spores were detected in any of the control samples.
When comparing infection rates among queens of different ages, queens aged 1 day after emergence were more susceptible to $N$. ceranae than older queens ( 6 and 12 days after emergence) (Figure 1a, b). The average number of spores in queens aged at 1 days postemergence that received a spore concentration of $10^{6} \mathrm{spores} / \mathrm{ml}$ was significantly higher than those in queens aged 6 and 12 days after emergence at 6 days of inoculation (KruskalWallis $H, P=0.03$ ) (Figure 1a). Moreover, there were significant differences in the number of spores between queens aged at 1, 6, and 12 days post-emergence when the cage in which the queen was received a spore suspension of $10^{5}$ spores/ml (Kruskal-Wallis $H, P=0.0001$ ) and $10^{6}$ spores $/ \mathrm{ml}$ (Kruskal-Wallis $H, P=0.004$ ) after 12 days inoculation (Figure 1b). The largest difference was exhibited in the $10^{5}$ spores $/ \mathrm{ml}$ spore dose inoculation. The numbers of $N$. ceranae spores present in queens experimentally inoculated immediately after emergence were about 6 and 73 times higher than that in queens experimentally inoculated at ages 6 and 12 days after emergence, respectively.

The queens aged 1 day post-emergence that received a spore suspension of $10^{6}$ spores $/ \mathrm{ml}$ all became infected and some spores (average of $N$. ceranae spores $=9.92 \times 10^{5}$ spores/queen, $\mathrm{SE}=$ $5.00 \times 10^{5}$ spores/queen) could be observed after only 6 days post-inoculation (Figure $1 \mathrm{a})$. In the lower spore inoculations $\left(10^{3}, 10^{4}\right.$ spores $\left./ \mathrm{ml}\right)$, $N$. ceranae spores could be observed after 12 days post-inoculation, with a $16.7 \%$ infection rate (Table II). The number of spores were $4.0 \times 10^{7}$ spores/queen $\left(\mathrm{SE}=8.66 \times 10^{6}\right.$ spores/ queen) and $3.1 \times 10^{7}$ spores/queen $(\mathrm{SE}=1.84 \times$ $10^{6}$ spores/queen), respectively, when inoculated with $10^{5}$ and $10^{6}$ spores $/ \mathrm{ml}$, with a $100 \%$ infection rate (Figure $1 \mathrm{~b}$ and Table II).

Of the queens aged 6 days post-emergence and then fed $N$. ceranae, they became infected when receiving a spore suspension of $10^{5}$ and $10^{6} \mathrm{spores} / \mathrm{ml}$, with an infection rate of 16.7 and $50 \%$ at 6 days post-inoculation, respectively (Figure 1a), and a $100 \%$ infection rate after 12 days post-inoculation (Table II). The average spore numbers were $6.64 \times 10^{6}$ spores/queen 

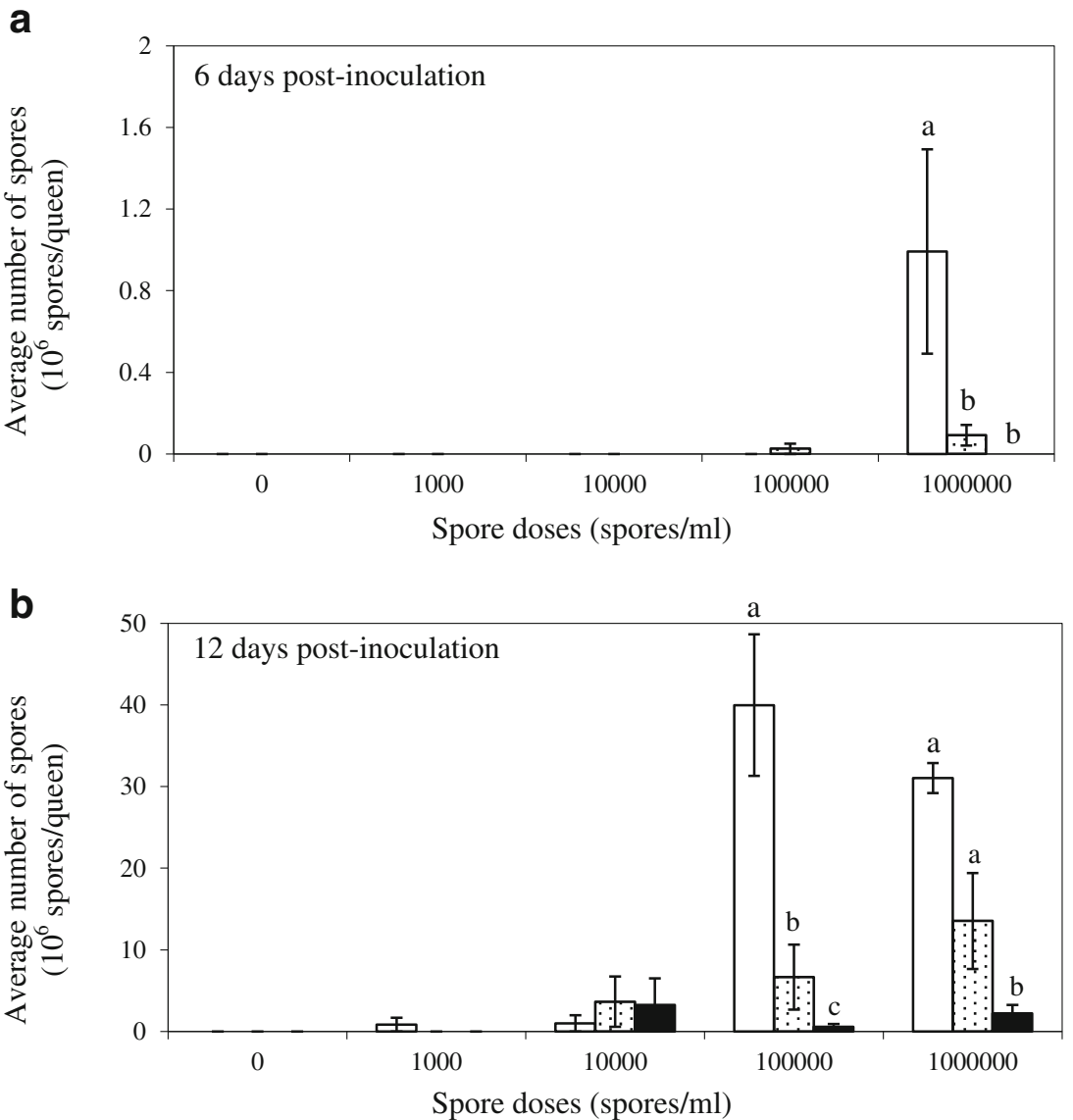

Queens inoculated when1 day old $\quad$ Queen inoculated when 6 days old

Queen inoculated when 12 days old

Figure 1. N. ceranae infection of different age honey bee queens at day 6 (a) and 12 (b) post-inoculation (mean of spore number $\pm \mathrm{SE}$ ). The queens aged 1,6 , and 12 days old were inoculated with $10^{3}, 10^{4}, 10^{5}$, and $10^{6}$ spores/ml. Vertical bars with different letters indicate significantly different means (Kruskal-Wallis $H$ and Mann-Whitney $U$ ).

$\left(\mathrm{SE}=3.99 \times 10^{6}\right.$ spores/queen $)$ and $1.352 \times 10^{7}$ spores/queen $\left(\mathrm{SE}=5.87 \times 10^{6}\right.$ spores/queen $)$ at 12 days after inoculation when the cage was inoculated with $10^{5}$ and $10^{6}$ spores $/ \mathrm{ml}$, respectively (Figure 1b).

When queens were aged for 12 days postemergence and then fed $N$. ceranae, no spores were observed in queens, 6 days postinoculation (Figure 1a). By 12 days postinoculation, the infection rates had increased to $16.7,33.3$, and $100 \%$ when inoculated with
$10^{4}, 10^{5}$, and $10^{6}$ spores $/ \mathrm{ml}$ respectively, indicating decreased susceptibility with increasing queen age (Figure 1 and Table II).

\subsection{Effects of $N$. ceranae infection on immune related gene expression in queen gut tissue}

Expression of immune-related genes, apidaecin, eater, and vitellogenin of queens of different ages inoculated with $N$. ceranae at the 
Table II. Percentage of $N$. ceranae infection in honey bee queen at different ages after inoculated with $N$. ceranae spore doses of $10^{3}-10^{6}$ spores $/ \mathrm{ml}$.

\begin{tabular}{|c|c|c|c|c|c|c|}
\hline \multirow{2}{*}{$\begin{array}{l}\text { Age of queen } \\
\text { (days after } \\
\text { emergence }\end{array}$} & \multirow{2}{*}{$\begin{array}{l}\text { Day of } \\
\text { inoculation } \\
\text { (days) }\end{array}$} & \multicolumn{5}{|c|}{ Percent of infection } \\
\hline & & Control & $10^{3}$ spores $/ \mathrm{ml}$ & $10^{4}$ spores $/ \mathrm{ml}$ & $10^{5}$ spores $/ \mathrm{ml}$ & $10^{6}$ spores $/ \mathrm{m}$ \\
\hline \multirow[t]{2}{*}{1} & 6 & 0 & 0 & 0 & 0 & 100 \\
\hline & 12 & 0 & 16.7 & 16.7 & 100 & 100 \\
\hline \multirow[t]{2}{*}{6} & 6 & 0 & 0 & 0 & 16.7 & 50 \\
\hline & 12 & 0 & 0 & 50 & 100 & 100 \\
\hline \multirow[t]{2}{*}{12} & 6 & 0 & 0 & 0 & 0 & 0 \\
\hline & 12 & 0 & 0 & 16.7 & 33.3 & 100 \\
\hline
\end{tabular}

spore dose of $10^{5}$ and $10^{6}$ spores $/ \mathrm{ml}$ was analyzed at 6 and 12 days post-inoculation. The tissues of gut and remaining abdomen were investigated for transcript levels of these genes. We found that gene expression varies with queen age.

In queens aged for 1 day post-emergence, there were no significant differences in gene expression of eater in gut tissues between inoculated and control queens after 6 days (ANOVA, $P>0.05$ ) (Figure 2a). Transcript levels of eater in queens inoculated with $10^{6}$ spores $/ \mathrm{ml}$ of $N$. ceranae were three times higher than those in control queens after 12 days of inoculation (Kruskal-Wallis $H, P>0.05$ ) (Figure 2d). The mRNA levels of apidaecin were significantly upregulated in $N$. ceranaeinoculated queens at day 6 of inoculations (ANOVA, $P<0.001$ ) (Figure $2 \mathrm{~b}$ ), with mean relative expression values of $-0.197 \pm 0.561$ s.e. and $-1.717 \pm 0.555$ s.e. for queens inoculated with $10^{5}$ and $10^{6}$ spores $/ \mathrm{ml}$ of $N$. ceranae, respectively. Whereas apidaecin expression was not significantly different between control and inoculated queens 12 days after inoculation (ANOVA, $P>0.05$ ) (Figure 2e).

The expression of vitellogenin was varied in queens when inoculated with $N$. ceranae. In inoculated queens with $10^{5}$ spores $/ \mathrm{ml}$, transcript levels of vitellogenin were significantly increased after 6 days of inoculation (ANOVA, $P=0.004$; mean relative expression of $-3.483 \pm$ 1.086 s.e.); however, there was significantly elevated in inoculated queens with $10^{6}$ spores/ $\mathrm{ml}$ of $N$. ceranae at day 12 inoculation (mean relative expression of $1.912 \pm 0.308$ s.e.).

In queens inoculated at 6 days postemergence, the gene expression of eater and vitellogenin in gut tissue was significantly lower in inoculated queens compared to control queens at 6 days post-inoculation (KruskalWallis $H, P=0.05$ and $P=0.03$, respectively). Transcript levels of eater were about four times lower than control queens, with average relative expression of $-14.968 \pm 0.500$ s.e. and -14.007 \pm 1.631 s.e. for $10^{5}$ and $10^{6}$ spores $/ \mathrm{ml}$ of $N$. ceranae-infected queens, respectively (Figure 2a). Also, vitellogenin expression in inoculated queens was about seven times lower than control queens (mean of $-5.757 \pm 0.265$ s.e. and $-4.217 \pm 1.000$ for $10^{5}$ and $10^{6}$ spores $/ \mathrm{ml}$ of $N$. ceranae-inoculated queens, respectively; Figure 2c). At day 12 post-inoculation, queens inoculated with $N$. ceranae concentration of $10^{6}$ spores $/ \mathrm{ml}$ showed higher expression of eater (ANOVA, $P=0.036$ ), with mean of $-13.903 \pm$ 0.306 s.e. (Figure 2d). Comparing inoculated and control queens, there were no significant differences in transcript levels of vitellogenin 12 days after inoculation (ANOVA, $P>0.05$ ) (Figure 2f). For apidaecin, the mRNA levels were not significantly different between inoculated and control queens at 6 and 12 days after inoculation (Kruskal-Wallis $H, P>0.05$ and ANOVA, $P>0.05$, respectively; Figure $2 \mathrm{~b}, \mathrm{e})$.

Gene expression of apidaecin and vitellogenin did not change in gut tissue of inoculated 

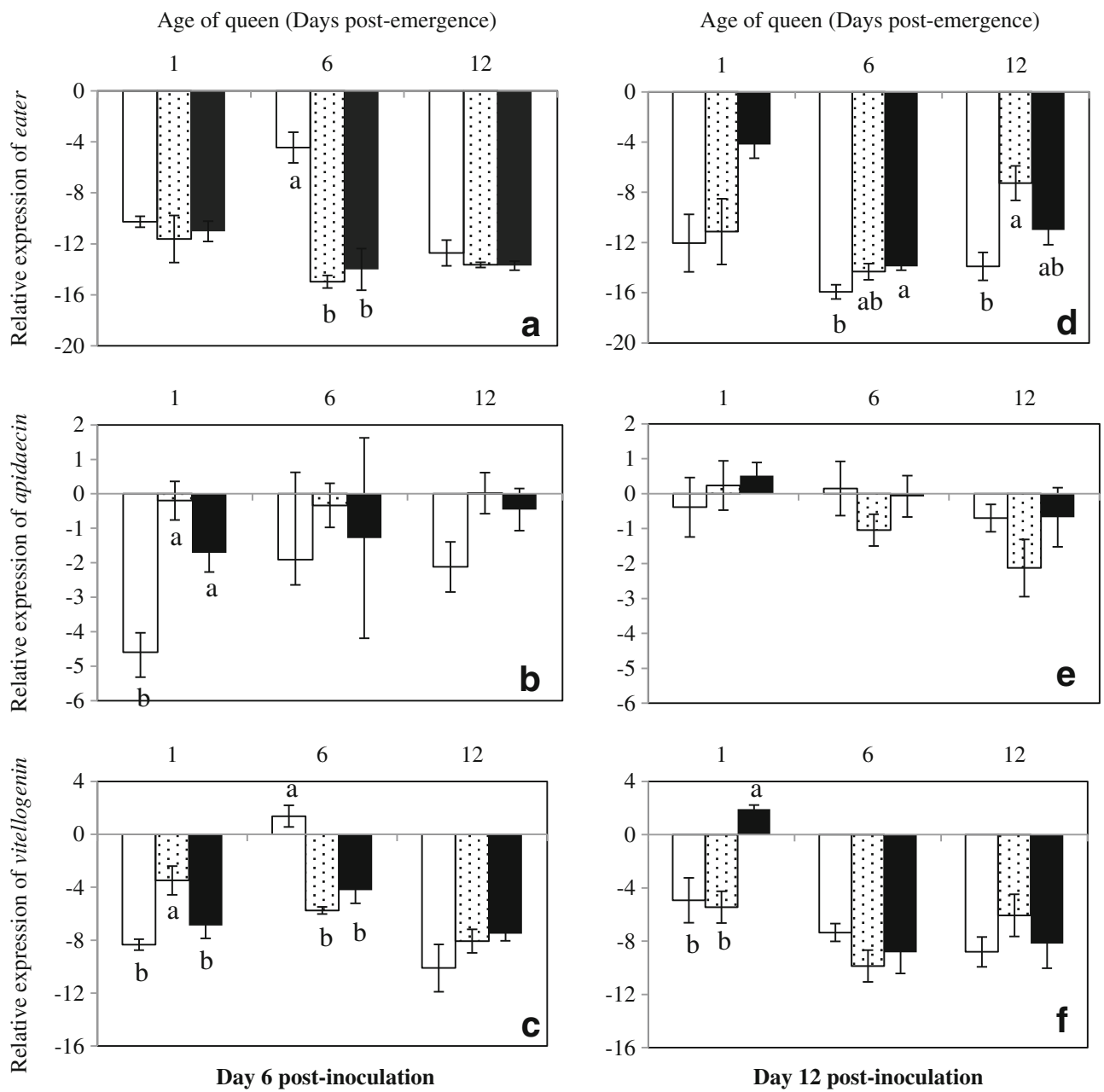

$\square$ Control queens $\quad::$ Queens inoculated with $10^{5}$ spores $/ \mathrm{ml}$ of $N$. ceranae

Queens inoculated with $10^{6}$ spores $/ \mathrm{ml}$ of $N$. ceranae

Figure 2. Effects of N. ceranae on the expression of eater, apidaecin, and vitellogenin in gut tissue of queens aged 1, 6, and 12 days post-emergence. Vertical bars with different letters show statistically significant differences (ANOVA, Kruskal-Wallis $H$, and Mann-Whitney $U$ ).

queens aged 12 days post-adult emergence after 6 and 12 days (ANOVA, $P>0.05$ ) (Figure 2b, c, e, f). However, eater mRNA was significantly upregulated in inoculated queens with $10^{5}$ spores/ $\mathrm{ml}$ (ANOVA, $P=0.006$; average of $-7.271 \pm$ 1.381 s.e.; Figure $2 \mathrm{~d}$ ).

\subsection{Effects of $N$. ceranae infection on immune related gene expression in the remaining abdomen of queens}

The mRNA levels of eater, apidaecin, and vitellogenin in the abdomens of inoculated and 
control queens aged 1, 6, and 12 days postemergence were also analyzed. Transcript levels of eater and vitellogenin in queens aged 1 day post emergence when inoculated with highest spore concentration of $N$. ceranae were significantly increased as compared with control queens (ANOVA, $P<0.001$ and Kruskal-Wallis $H, P=0.001$, respectively; Figure $3 \mathrm{a}, \mathrm{c})$. The average relative expression for eater and vitel- logenin was $0.253 \pm 0.229$ s.e. and $0.898 \pm$ 0.140 s.e., respectively. In contrast, apidaecin transcripts were suppressed in inoculated queens and significant expression was obtained in inoculated queens with $10^{6} \mathrm{spores} / \mathrm{ml}$ at 6 days post-inoculation (ANOVA, $P=0.041$ ), with mean of $-0.280 \pm 0.731$ s.e. (Figure $3 b$ ). Of queens aged 6 days post-adult emergence, the expression of eater and vitellogenin in inocu-
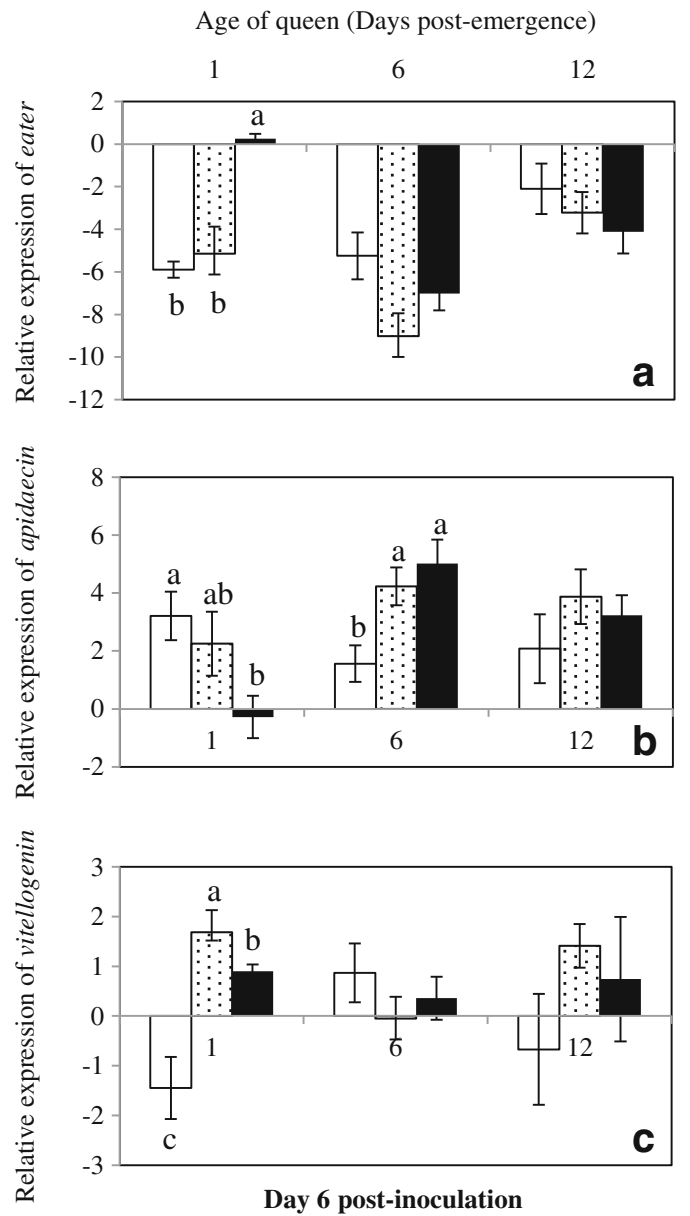

Age of queen (Days post-emergence)
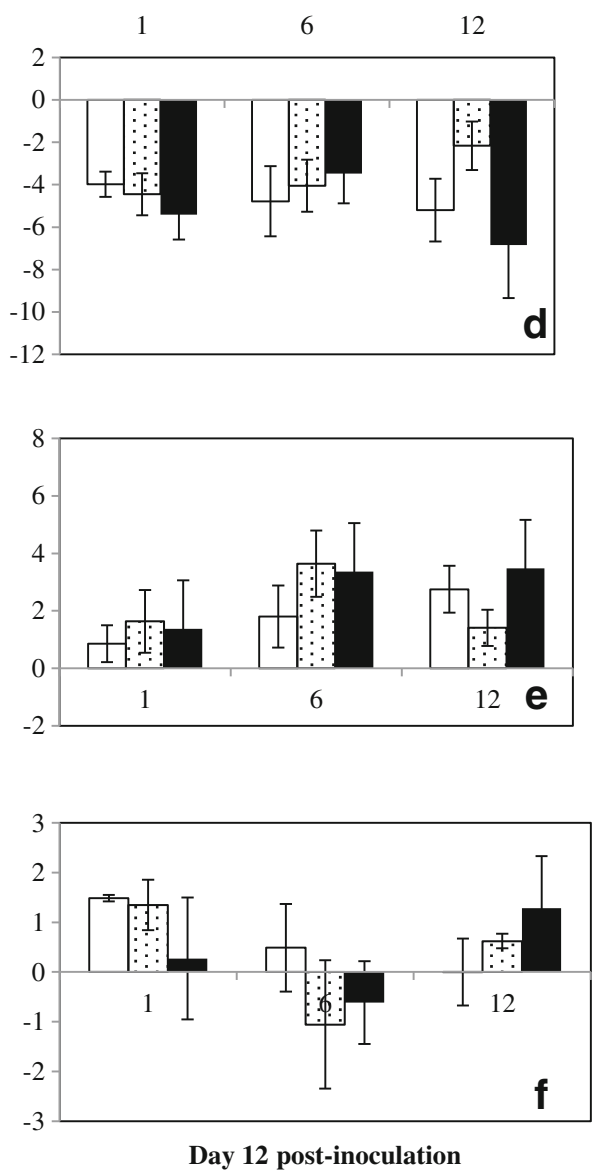

Control queens Queens inoculated with $10^{5}$ spores $/ \mathrm{ml}$ N. ceranae

Queens inoculated with $10^{6}$ spores $/ \mathrm{ml}$ N. ceranae

Figure 3. Effects of $N$. ceranae on the expression of eater, apidaecin, and vitellogenin in the remaining abdomen tissue of queens aged 1, 6, and 12 days post-emergence. Vertical bars with different letters show statistically significant differences (ANOVA, Kruskal-Wallis $H$ and Mann-Whitney $U$ ). 
lated queens was lower than those in control queens after 6 days, but not significantly different (ANOVA, $P>0.05$ ). The mRNA levels of apidaecin were about three times higher in inoculated queens than in control queens (ANOVA, $P=0.009$ ). The average relative expression was $4.230 \pm 0.654$ s.e. and $5.022 \pm$ 0.820 s.e. for $10^{5}$ and $10^{6}$ spores $/ \mathrm{ml}$ of $N$. ceranae-inoculated queens, respectively. Comparing inoculated and control queens aged 12 days post-adult emergence, transcript levels of apidaecin and vitellogenin in inoculated queens increased as compared to the control after 6 days inoculation (ANOVA and KruskalWallis $H, P>0.05$; Figure $3 b$ ). By contrast, eater expression in inoculated queens was lower than that in control queens (ANOVA, $P>0.05$; Figure 3a). Finally, there were no significant differences in mRNA levels of eater, apidaecin, and vitellogenin in abdomens of all queens after 12 days post-inoculation (Kruskal-Wallis $H$, $P>0.05$; Figure $3 \mathrm{~d}-\mathrm{f}$ ).

\subsection{Expression levels in the gut and remaining abdomen of queens at different ages}

The mRNA levels for the antimicrobial peptide apidaecin, and for eater and vitellogenin, were measured for different-aged queens (queens aged 6, 12, 18, and 24 days old postadult emergence; Figure 4). For eater, the mRNA levels in gut tissue of queens aged 18 and 24 days post-adult emergence were significantly lower than those of younger queens (queens aged 6 and 12 days old post-adult emergence; Kruskal-Wallis $H, P=0.014$; Figure 4). Older queens had about 1.6 times lower transcript levels than younger queens with average of $-14.329 \pm 0.734$ s.e. and $-13.903 \pm$ 1.115 s.e. for queens aged 18 and 24 days old, respectively. In contrast, transcript levels of eater in the remaining abdomens of the younger queens were not significantly different from those of the older queens (ANOVA, $P>0.05$; Figure 4). Apidaecin transcript levels in the gut were sequentially increased in the older queens (Kruskal-Wallis $H, P=0.007$ ). However, mRNA levels of apidaecin in remaining abdomen decreased in the older queens but no significant differences could be obtained (Kruskal-Wallis $H$, $P>0.05)$. For vitellogenin, the mRNA levels in the gut and remaining abdomen were significantly higher in queens aged 12 days old post-adult emergence than in queens aged 6, 18, and 24 days old post-adult emergence (ANOVA, $P<0.001$ and Kruskal-Wallis $H, P=0.010$ in the tissues of gut and remaining abdomen, respectively), with means of $-1.777 \pm 1.303$ s.e. and $1.177 \pm$ 0.700 s.e. for gut and remaining abdomen, respectively.

\section{DISCUSSION}

In this study, we examined the effect of both queen age and spore dose on the susceptibility of queen honey bees to $N$. ceranae infection. The 12day period after emergence was selected as it corresponds with the time that queens often kept in small nucleus colonies for mating before being shipped to the beekeeper. We clearly show that queens become less susceptible as they age making their time spent in the mating nuclei critical for $N$. ceranae infection. Our results suggest that any measures that reduce the contamination of $N$. ceranae spores in food sources fed to the newly emerged queens would help to prevent queens from becoming infected with $N$. ceranae.

The results show that queens become infected when inoculated with a high dose of either $10^{5}-10^{6}$ spores $/ \mathrm{ml}$ of $N$. ceranae spores, 12 days post-inoculation, except for those queens aged for 12 days, when only those queens dosed with $10^{6}$ spores $/ \mathrm{ml}$ became $100 \%$ infected. $N$. ceranae fed spores at lower dosages of $10^{3}$ and $10^{4}$ spores $/ \mathrm{ml}$ did not infect all queens. Younger queens are more susceptible to $N$. ceranae infection than older queens. This age response could be interpreted as the young queen gut cells promoting the growth, development, and germination of $N$. ceranae (Keeling and Fast 2002). Nevertheless, Rinderer and Elliot (1977) indicated that the protein conditions of the host are critical for the development of $N$. apis. It is conceivable that younger queens are in better condition than older queens that 

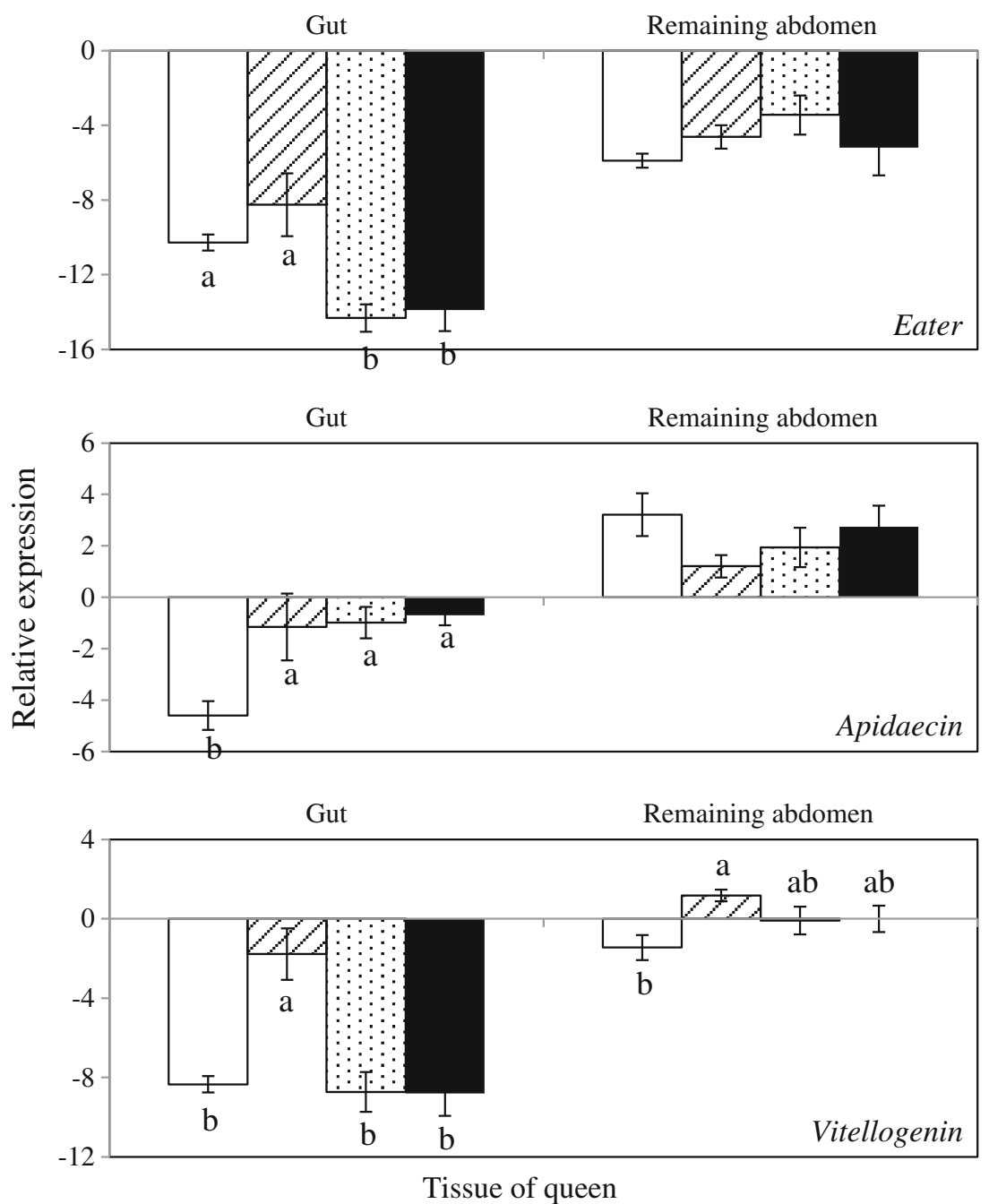

$\square$ Queen aged 6 days post adult emergence

$\square$ Queen aged 12 days post adult emergence

Queen aged 18 days post adult emergence

Queen aged 24 days post adult emergence

Figure 4. Expression levels of eater, apidaecin, and vitellogenin in the tissues of gut and remaining abdomen of queens of different ages. Vertical bars with different letters indicate significantly different means (ANOVA, Kruskal-Wallis $H$ and Mann-Whitney $U$ ).

have been exposed to periods of protein depletion. If queens are more susceptible during this initial period of adult life then mitigation measures could reduce $N$. ceranae infection and 
improve queen health and longevity in colonies. When considering the queens aged for 1 day postemergence, surprisingly the average number of spores in inoculated queens with $10^{5}$ spores $/ \mathrm{ml}$ of $N$. ceranae was higher than those in queens when inoculated with $10^{6}$ spores $/ \mathrm{ml}$. As all honey bee queens originated from the same queen breeder, we suggest that the susceptibility differences likely reflect the genetic variations of host at the individual queen level. The individual immune defense can be considered one of the benefits of genetic diversity in honey bees.

Honey bee queens of all three ages $(1,6$, and 12 days) inoculated by $N$. ceranae showed downregulation of eater in gut tissue after 6 days inoculation. A significant downregulation of eater was especially evident in queens aged 6 days postadult emergence. Eater transcripts after 12 days post-inoculation were upregulated in all queen ages when inoculated with $N$. ceranae. The results suggest that queens may have to produce more eater in this period to defend against $N$. ceranae infection. Since $N$. ceranae spores can rapidly develop and multiply during day 4 to 7 of infection. Thus, eater may play important role to eliminate this pathogen. Also eater has been shown to play a role in the phagocytosis of bacterial pathogens (Ertürk-Hasdemir and Silverman 2005; Kocks et al. 2005).

For apidaecin, the upregulation of this gene was observed in the gut of inoculated queens of all ages at 6 days post-inoculation. Our results revealed that $N$. ceranae induces apidaecin expression in queens in early periods of inoculation. However, apidaecin expression shows an opposing response between queens and workers after inoculated with $N$. ceranae. $N$. ceranae infection suppresses immune gene response in worker bees (Autúnez et al. 2009; Chaimanee et al. 2012). Queens might be better able to defend themselves from pathogen invasion since they produce more antimicrobial peptides. Nevertheless, different immune signaling between queens and workers following $N$. ceranae infection cannot be excluded.

Our study demonstrates great variation in vitellogenin expression between queens of different ages. Vitellogenin transcripts were increased in inoculated queens aged 1 and 12 days post-emergence in both of gut and remaining abdomen tissues. However, queens showed decreased expression when aged 6 days old. In a recent study, Alaux et al. (2011) reported that the vitellogenin titer increased about $58 \%$ in honey bee queens when infected with $N$. ceranae. In contrast, Autúnez et al. (2009) demonstrated that the mRNA levels of vitellogenin in $N$. ceranae infected worker bees significantly decreased after 7 days of infection. Vitellogenin is a female-specific glucolipoprotein yolk precursor synthesized in the fat body of abdomen (Byrne et al. 1989). It plays an important function in immunity and longevity of worker honey bees (Amdam et al. 2004). Therefore, it is not conclusive that vitellogenin is affected by $N$. ceranae infection in queens. Other factors may contribute to the expression of the vitellogenin gene.

Differences in the transcript levels of genes were clearly observed between the gut and remaining abdomen. Our results showed that the expression of eater, apidaecin, and vitellogenin in the gut was lower than that from the remaining abdomen. Not surprisingly, since the fat body distributes throughout the abdomen and it is the site of antimicrobial peptides synthesis. The results showed that eater transcripts were decreased in the gut tissue and there were elevated in the abdomen part of older queens. Contrary to eater expression, the mRNA levels of apidaecin in the gut of queens were increased in older queens. This indicates that younger queens produce lower apidaecin levels than older queens and may help explain the increased susceptibility of younger queens to $N$. ceranae. In this study, we showed that vitellogenin expression in the gut and abdomen did not differ between queens aged 6,18 , and 24 days old post-emergence, except in queens aged 12 days where there was a significant vitellogenin production compared to the others. In honey bee queens, vitellogenin synthesis starts $60 \mathrm{~h}$ before adult emergence and vitellogenin titers stays high thereafter (Barchuk et al. 2002). Moreover, Corona et al. (2007) have reported that older queens have higher vitellogenin transcript levels than do young queens. Surprisingly, queens aged 12 days old had the highest vitellogenin 
expression in our study. We hypothesize that high vitellogenin level may result from immunity, hormone signaling, and/or oxidative stress. Taken together, we suggest that vitellogenin expression in queens does not vary greatly between ages 6 to 24 days of age.

\section{ACKNOWLEDGMENTS}

V.C. was supported by a grant under the program of Strategic Scholarships for Frontier Research Network for the Joint Ph.D. Program Thai Doctoral degree from the Office of the Higher Education Commission, Thailand. We thank the Thailand Research Fund (BRG 5580013), National Research University, Office of Higher Education Commission, and the USDA-ARS Bee Research Laboratory for financial support. We thank M. Hamilton, D. Lopez, V. Levi, and N. Rice for their excellent technical help with the project.

\section{OPEN ACCESS}

This article is distributed under the terms of the Creative Commons Attribution License which permits any use, distribution, and reproduction in any medium, provided the original author(s) and the source are credited.

Effets de l'âge de l'hôte sur la sensibilité à l'infection et sur l'expression d'un gène immunitaire chez les reines d'abeille (Apis mellifera) inoculées avec Nosema ceranae

Abeille / reine / peptides anti-microbiens / supercédure

Einfluss des Wirtsalters auf die Infektionsanfälligkeit und die Expression von Immungenen bei Honigbienenköniginnen (Apis mellifera), die mit Nosema ceranae infiziert wurden

Nosema ceranae / Honigbienenkönigin / Apis mellifera / Umweiselung / antimikrobielle Peptide

\section{REFERENCES}

Alaux, C., Brunet, J.L., Dussaubat, C., Mondet, F., Tchamichan, S., Cousin, M., Brlllard, J., Baldy, A., Belzunces, L.P., Conte, Y.L. (2010) Interactions between Nosema microspores and a neonicotinoid weaken honeybees (Apis mellifera). Environ. Microbiol. 12, 774-782
Alaux, C., Folschweiller, M., McDonnell, C., Beslay, D., Cousin, M., Dussaubat, C., Brunet, J.L., Conte, Y.L. (2011) Pathological effects of the microsporidium Nosema ceranae on honey bee queen physiology (Apis mellifera). J. Invertebr. Pathol. 106, 380-385

Amdam, G.V., Simões, Z.L.P., Hagen, A., Norberg, K., Schroder, K., Mikkelsen, O., Kirkwood, T.B.L., Omholt, S.W. (2004) Hormonal control of yolk precursor vitellogenin regulates immune function and longevity in honeybees. Exp. Gerontol. 39, 767-773

Antúnez, K., Martín-Hernández, R., Prieto, L., Meana, A., Zunino, P., Higes, M. (2009) Immne suppression in the honey bee (Apis mellifera) following infection by Nosema ceranae (Microsporidia). Environ. Microbiol. 11, 2284-2290

Barchuk, A.R., Bitondi, M.M.G., Simões, Z.L.P. (2002) Effects of juvenile hormone and ecdysone on the timing of vitellogenin appearance in hemolymph of queen and worker pupae of Apis mellifera. J. Insect Sci. 2, e8

Byrne, B.M., Gruber, M., Ab, G. (1989) The evolution of egg yolk proteins. Prog. Biophys. Mol. Biol. 53, 33-69

Cantwell, G.E. (1970) Standard methods for counting Nosema spores. Am. Bee J. 110, 222-223

Chaimanee, V., Chantawannakul, P., Chen, Y., Evans, J.D., Pettis, J.S. (2012) Differential expression of immune genes of adult honey bee (Apis mellifera) after inoculated by Nosema ceranae. J. Insect Physiol. 58, 1090-1095

Chaimanee, V., Warrit, N., Chantawannakul, P. (2010) Infections of Nosema ceranae in four different honeybee species. J. Invertebr. Pathol. 105, 207-210

Chauzat, M.P., Higes, M., Martín-Hernández, R., Meana, A., Cougoule, N., Faucon, J.P. (2007) Presence of Nosema ceranae in French honeybee colonies. J. Apic. Res. 46, 127-128

Chen, Y.P., Evans, J.D., Murphy, C.A., Gutell, R., Zuker, M., Gundersen-Rindal, D.E., Pettis, J.S. (2009) Morphological, molecular, and phylogenetic characterization of Nosema ceranae, a microsporidian parasite isolated from the European honey bee, Apis mellifera. J. Eukaryot. Microbiol. 56, 142-147

Chen, Y., Evans, J.D., Smith, I.B., Pettis, J.S. (2008) Nosema ceranae is a long-present and wide-spread microsporidian infection of the European honey bee (Apis mellifera) in the United States. J. Invertebr. Pathol. 97, 186-188

Cornman, R.S., Tarpy, D.R., Chen, Y.-P., Jeffreys, L., Lopez, D., Pettis, J.S., vanEngelsdorp, D., Evans, J.D. (2012) Pathogen webs in collapsing honey bee colonies. PLoS ONE 7, e43562

Corona, M., Velarde, R.A., Remolina, S., Moran-Lauter, A., Wang, Y., Hughes, K.A., Robinson, G.E. (2007) Vitellogenin, juvenile hormone, insulin signaling, and queen honey bee longevity. Proc. Nat. Acad Sci. USA 104, 7128-7133 
Cox-Foster, D.L., Conlan, S., Homles, E.C., Palacios, G., Evans, J.D., et al. (2007) A metagenomic survey of microbes in honey bee colony collapse disorder. Science 318, 283-287

Dussaubat, C., Brunet, J.L., Higes, M., Colbourne, J.K., Lopez, J., et al. (2012) Gut pathology and responses to the microsporidium Nosema ceranae in the honey bee Apis mellifera. PLos ONE 7, e37017

Dussaubat, C., Maisonnasse, A., Alaux, C., Tchamitchan, S., Brunet, J.L., Plettener, E., Belzunces, L.P., Le Conte, Y. (2010) Nosema spp. infection alters pheromone production in honey bee (Apis mellifera). J. Chem. Ecol. 36, 522-525

Dussaubat, C., Maisonnasse, A., Crauser, D., Beslay, D., Costagliola, G., Soubeyrand, S., Kretzchmar, A., Le Conte, Y. (2013) Flight behavior and pheromone changes associated to Nosema ceranae infection of honey bee workers (Apis mellifera) in field conditions. J. Invertebr. Pathol. 113, 42-51

Ertürk-Hasdemir, D., Silverman, N. (2005) Eater: a big bite into phagocytosis. Cell 123, 190-192

Evans, J.D. (2006) Beepath: an ordered quantitativePCR array for exploring honey bee immunity and disease. J. Invertebr. Pathol. 93, 135-139

Farrar, C.L. (1947) Nosema losses in package bees as related to queen supersedure and honey yields. J. Econ. Entomol. 40, 333-338

Fries, I., Feng, F., Silva, A.D., Slemenda, S.B., Pieniazek, N.J. (1996) Nosema ceranae n. sp. (Microspora, Nosematidae), Morphological and molecular characterization of a microsporidian parasite of the Asian honey bee Apis cerana (Hymenoptera, Apidae). Eur. J. Protistol. 32, 356-365

Fries, I., Martín, R., Meana, A., García-Palencia, P., Higes, M. (2006) Natural infections of Nosema ceranae in European honey bees. J. Apic. Res. 45, 230-233

Goblirsch, M., Huang, Z.Y., Spivak, M. (2013) Physiological and behavioral changes in honey bees (Apis mellifera) induced by Nosema ceranae infection. PLoS ONE 8, e58165

Higes, M., García-Palencia, P., Martín-Hernández, R., Meana, A. (2007) Experimental infection of Apis mellifera honeybees with the Microsporidia Nosema ceranae. J. Invertebr. Pathol. 94, 211217

Higes, M., Martín-Hernández, R., García-Palencia, P., Marín, P., Meana, A. (2009) Horizontal transmission of Nosema ceranae (Microsporidia) from worker honeybees to queens (Apis mellifera). Environ. Microbiol. Rep. 1, 495-498

Higes, M., Martín, R., Meana, A. (2006) Nosema ceranae, a new microsporidian parasite in honeybees in Europe. J. Invertebr. Pathol. 92, 93-95
Huang, W.F., Jiang, J.H., Chen, Y.W., Wang, C.H. (2007) A Nosema ceranae isolate from the honeybee Apis mellifera. Apidologie 38, 30-37

Keeling, P.J., Fast, N.M. (2002) Microsporidia: biology and evolution of highly reduced intracellular parasites. Annu. Rev. Microbiol. 56, 93-116

Klee, J., Besana, A.M., Genersch, E., Gisder, S., Nanetti, A., et al. (2007) Widespread dispersal of the microsporidian Nosema ceranae, an emergent pathogen of the western honey bee, Apis mellifera. J. Invertebr. Pathol. 96, 1-10

Kocks, C., Cho, J.H., Nehme, N., Ulvila, J., Pearson, A.M., et al. (2005) Eater, a transmembrane protein mediating phagocytosis of bacterial pathogens in Drosophila. Cell 123, 335-346

Malone, L.A., Giacon, H.A., Newton, M.R. (1995) Comparison of the responses of some New Zealand and Australia honey bees (Apis mellifera L) to Nosema apis Z. Apidologie 26, 495-502

Martín-Hernández, R., Botías, C., Barrios, L., MartínezSalvador, A., Meana, A., Mayack, C., Higes, M. (2011) Comparison of energetic stress associated with experimental Nosema ceranae and Nosema apis infection of honeybees (Apis mellifera). Parasitol. Res. 3, 605-612

Mayack, C., Naug, D. (2009) Energetic stress in the honeybee Apis mellifera from Nosema ceranae infection. J. Invertebr. Pathol. 100, 185-188

Mayack, C., Naug, D. (2010) Parasitic infection leads to decline in hemolymph sugar levels in honeybee foragers. J. Insect Physiol. 56, 1572-1575

Paxton, R., Klee, J., Korpela, S., Fries, I. (2007) Nosema ceranae has infected Apis mellifera Europe in at least 1998 and may be more virulent than Nosema apis. Apidologie 38, 558-565

Rinderer, T.E., Elliott, K.D. (1977) Worker honey bee response to infection with Nosema apis: influence of diet. J. Econ. Entomol. 70, 431-433

Simone, M., Evans, J.D., Spivak, M. (2009) Resin collection and social immunity in honey bees. Evolution 11, 3016-3022

Traver, B.E., Fell, R.D. (2012) Low natural levels of Nosema ceranae in Apis mellifera queens. J. Invertebr. Pathol. 110, 408-410

Webster, T.C. (1993) Nosema apis spore transmission among honey bees. Am. Bee J. 133, 869-870

Williams, G.R., Shafer, A.B.A., Rogers, R.E.L., Shutler, D., Stewart, D.T. (2008) First detection of Nosema ceranae, a microsporidian parasite of European honey bees (Apis mellifera), in Canada and central USA. J. Invertebr. Pathol. 97, 189-192

Zander, E. (1909) Tierische Parasiten als Krankenheitserreger bei der Biene. Münch. Bienenztg. 31, 196-204. 